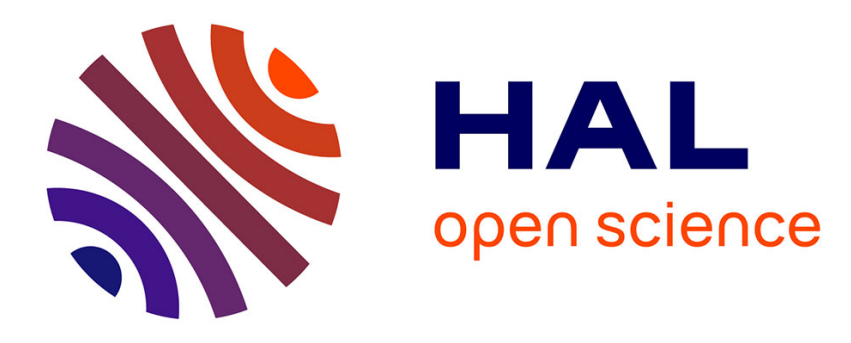

\title{
Sintering mechanisms of metals under electric currents Jean-Philippe Monchoux
}

\section{To cite this version:}

Jean-Philippe Monchoux. Sintering mechanisms of metals under electric currents. Spark Plasma Sintering of Materials, Springer International Publishing, pp.93-115, 2019, 978-3-030-05327-7. 10.1007/978-3-030-05327-7_4. hal-02390066

\section{HAL Id: hal-02390066 https://hal.science/hal-02390066}

Submitted on 2 Dec 2019

HAL is a multi-disciplinary open access archive for the deposit and dissemination of scientific research documents, whether they are published or not. The documents may come from teaching and research institutions in France or abroad, or from public or private research centers.
L'archive ouverte pluridisciplinaire HAL, est destinée au dépôt et à la diffusion de documents scientifiques de niveau recherche, publiés ou non, émanant des établissements d'enseignement et de recherche français ou étrangers, des laboratoires publics ou privés. 


\title{
Sintering mechanisms of metals under electric currents
}

\author{
Jean-Philippe Monchoux ${ }^{1}$ \\ ${ }^{1}$ CEMES CNRS UPR 8011, and Université de Toulouse, 29 Rue Jeanne Marvig, 31055 \\ Toulouse, France. \\ monchoux@cemes.fr
}

\begin{abstract}
This chapter concerns the microscopic mechanisms involved in densification of metallic powders submitted to high electric current pulses like in the SPS technique. Because metallic systems exhibit high electric conductivity, focus is made on evaluating the sensitivity of the densification mechanisms on the current. Thus, a first part is devoted to the influence of electric currents on elementary metallurgical phenomena (diffusion, plasticity...) which are involved in densification. Then, after recalling the micromechanical models of densification, the SPS kinetics is described, and analyzed in the framework of these models, with emphasis on the role of the current. Finally, theoretical and experimental investigations on electrically-induced mechanisms at the scale of the powder particle contacts, are presented: dielectric breakdown of oxide layers, arcs and plasma, Joule overheating, electroplasticity and electromigration. Then, conclusions are drawn on the most probable mechanisms, and on the role of the current.
\end{abstract}

Keywords: Densification mechanisms, electromigration, electroplasticity, kinetics, microstructural characterization, modelling

\section{Introduction}

From the two last decades, elaboration techniques based on use of high current intensities, among which the SPS technique is probably the most popular, have attracted considerable interest. In the case of the SPS, the reason of the fast development of this technique throughout the word is its unprecedented rapidity, which allows obtaining materials in typically $\sim 30 \mathrm{~min}$. For metals, this feature is particularly interesting, because short processing durations allow keeping fine microstructures, and consequently, elevated strengths. This remarkable processing rapidity was however poorly understood, and many studies have focused on investigating its physical bases. In particular, because the metallic systems exhibit, among the 
other classes of materials, the highest electrical conductivity, the influence of electric current on the microscopic mechanisms and on the densification kinetics have been actively investigated. The hypotheses is that the SPS current $\left(\sim 100 \mathrm{~A} / \mathrm{cm}^{2}\right)$ could accelerate the elementary metallurgical mechanisms involved in densification, and thus account for the rapidity of this technique.

Hence, a rapid review of the effects of electric currents in metallic systems will first be carried out. Then, relevant theoretical relations of densification under uniaxial pressure will be recalled, and typical SPS densification cycles of metallic systems will be given. Finally, a last section will be devoted to studies on the densification mechanisms at the microscopic scale, both by experiments and simulations.

\section{Effects of electric currents in metallic systems}

The effects of electric current in metallurgical processes have been studied since at least the 1930's. The influence of current on plasticity, diffusion, phase transformations has then been investigated, the most known effect being probably electromigration because of its role in microelectronics. The development of the SPS in the 1990's - 2000's induced studies focusing on the influence of electric currents on diffusion, because this elementary mechanism is involved in the sintering processes. As for studies on plasticity, also involved in the densification mechanisms, they are somewhat scarcer.

\subsection{Electric effects on mass transport and reactivity}

The motivation to study the effect of electric current on mass transport was primarily fundamental, because these investigations allowed to precise the interactions between the electrons and the point defects. The first studies, reviewed in Ref. (Adda 1966), treated the problem in the framework of the phenomenological theory of diffusion, then on the basis of atomistic calculations of momentum transfer by the electrons. These works considered that the diffusing species exhibit an "effective charge" $z^{*}$, which allows to take into account that the actual force applied on the diffusing species is composed of the regular electrostatic force, plus a contribution coming from the momentum transfer of the electrons. Values of $z^{*}$ are often elevated, and negative (typically, between -5 and -20 , e.g. Ni: $-5, \mathrm{Au}:-8.8$, Ag: $24 \ldots$ ), leading to migration toward the anode, but can also be positive (e.g. Co: $+1.6, \mathrm{Cu}:+12$, Fe: $+43 \ldots)$ for migration toward the cathode. This effect leads to the following differential equation for the diffusion profiles (Adda 1966, Shewmon 1989):

$\frac{\partial c}{\partial t}=D \frac{\partial^{2} c}{\partial x^{2}}-\frac{D}{R T} F Z^{*} \rho \cdot J \cdot \frac{\partial c}{\partial x}$ 
where $D$ is the diffusion coefficient (supposed independent on composition), $J$, current density, $c$, concentration, $F$, the Faraday's constant, $R$, the gas constant, $T$, temperature, $x$, spatial coordinate, and $t$, time. The resolution of this equation, which is a modification of the second Fick's law, leads to a temporal drift of the diffusion profiles for current densities $\sim 10^{3}-10^{4} \mathrm{~A} / \mathrm{cm}^{2}$ and durations $\sim 100-500 \mathrm{~h}$ (Fig. 1).

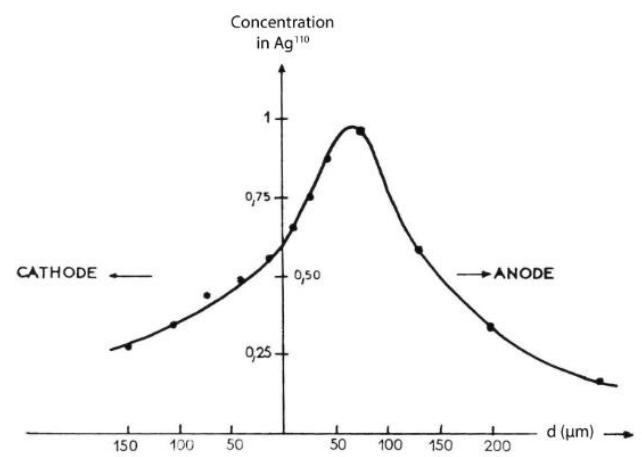

Fig. 1 Migration in $\mathrm{Ag}$ of $\mathbf{A g}^{110}$ markers initially positioned at $x=0$ in presence of a current. The influence of the current is seen by the displacement of the maximum of the profile toward the anode. Conditions: $J=6800 \mathrm{~A} / \mathrm{cm}^{2}, T=820^{\circ} \mathrm{C}, t=160 \mathrm{~h}$ (Adda 1966).

But the most popular effect of an electric current on materials is indisputably the failure of electronic interconnects by electromigration. Due to the reduction of the interconnect sections to the micrometer scale, which allows fast dissipation of the heat generated by Joule effect, very strong current densities $\left(\sim 10^{6}-10^{7} \mathrm{~A} / \mathrm{cm}^{2}\right)$ can be achieved. These considerable current densities generate mass transfer (Fig. 2) which can provoke rupture of connections after typical durations of $\sim 10^{2}-10^{3} \mathrm{~h}$ (Frankovic 1996).
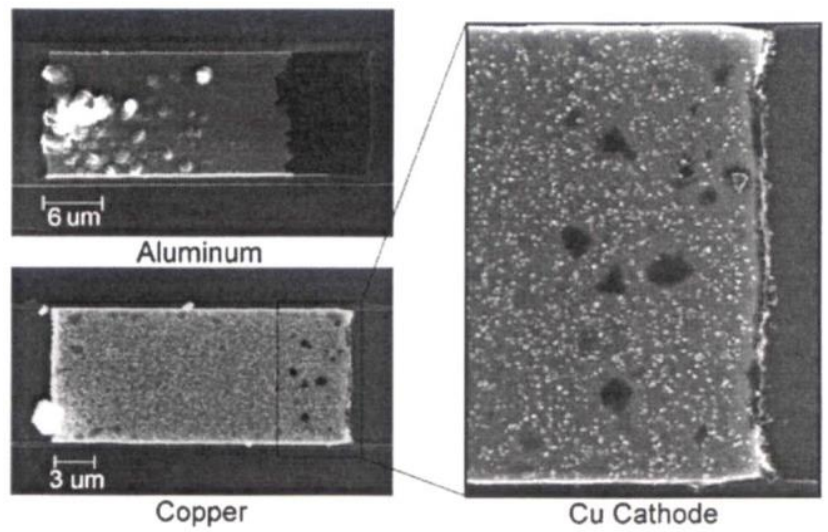

Fig. $2 \mathrm{Al}$ and $\mathrm{Cu}$ conductor segments submitted to a current density of $6 \times 10^{5} \mathrm{~A} / \mathrm{cm}^{2}$ in the following conditions: $250^{\circ} \mathrm{C}-336 \mathrm{~h}$ for $\mathrm{Cu}, 200^{\circ} \mathrm{C}-500 \mathrm{~h}$ for $\mathrm{Al}$ (electron sense: from right to left). Note the depletion of matter at the cathode and its accumulation at the anode (Frankovic 1996). 
Finally, the influence of an electric current of $\sim 10^{2}-10^{3} \mathrm{~A} / \mathrm{cm}^{2}$ in experiments lasting $t \sim 10-500 \mathrm{~h}$ on reactivity of many metallic systems has been studied around the year 2000, in the context of the development of sintering and synthesis techniques under electrical solicitations. Thus, experiments with electric currents passing through diffusion couples have been performed in the following systems: Al-Ni (Liu et al. 1998), Sn-Cu and Sn-Ni (Chen et al. 1998, Wang et al. 2011), Sn-Ag (Chen et al. 1999), Bi-Ni (Chen et al. 2000), Al-Au (Bertolino et al 2001), Ni-Ti (Garay et al. 2003, Zhou et al. 2011), Cu-Ni (Zhao et al. 2007) and Ag-Zn (Friedman et al. 2004). In all these study, electric currents were reported to significantly modify the growth kinetics of intermetallic layers, and to modify diffusion profiles. For example, Fig. 3 shows the example of a Al-Ni diffusion couple annealed at $400^{\circ} \mathrm{C}$ for $336 \mathrm{~h}$ and submitted to a current of $1000 \mathrm{~A} / \mathrm{cm}^{2}$. It can be seen that the layer is wider with current passing through the sample than without. The effect can be either dependent ("vectorial effect") or independent ("scalar effect") of the current direction. The interpretation of these phenomena remains largely unclear. There could be an influence of electromigration mechanisms (momentum transfer of the electrons), but other interpretations are based on influence of the current on equilibrium point defect concentration (Conrad 2000, Munir 2006) or on mobility activation energy (Munir 2006). However, in electromigration experiments in which the temperature profiles were carefully controlled, no effect of high currents $\left(\sim 10^{3} \mathrm{~A} / \mathrm{cm}^{2}\right)$ was detected in the Ag-Zn system (Trzaska and Monchoux 2015), contradicting a previous study (Friedman et al. 2004).
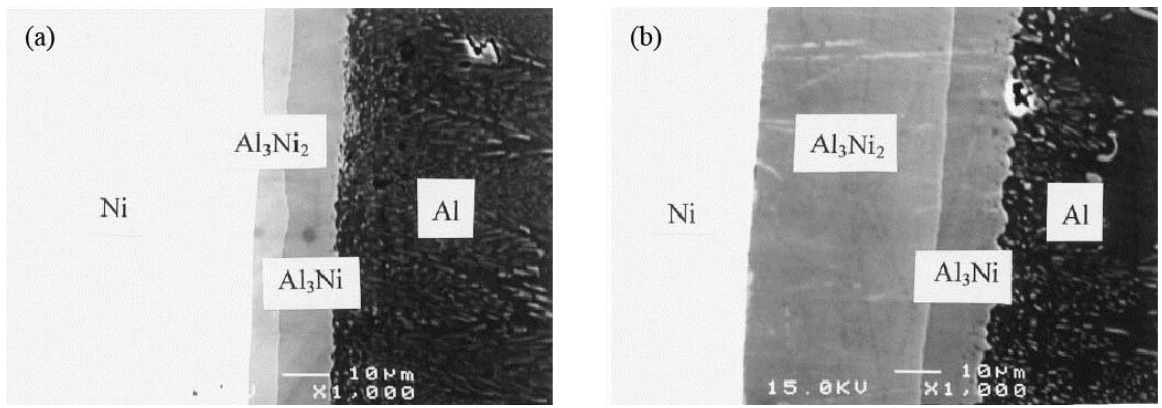

Fig. 3 Micrographs of a Al-Ni diffusion couple annealed at $400^{\circ} \mathrm{C}$ for $336 \mathrm{~h}$ (a) without current, and (b) with a current of $1000 \mathrm{~A} / \mathrm{cm}^{2}$ passing through the sample (Liu e al. 1998).

\subsection{Electric effects on plasticity and on other metallurgical mechanisms}

Some studies have focused on the influence of current on metallurgical phenomena, as plasticity, recrystallization, phase transformations... These studies are interesting in the framework of the understanding of the SPS processes, to account for the impact of the current on the final microstructures obtained by this technique. Moreover, plasticity can also be involved in sintering, as described later, and the 
influence of a current on this mechanism could allow to deeper understand the SPS kinetics. Unfortunately, studies on electric effects on these metallurgical phenomena are rather scarce and most of the time controversial. Here is a short report about the main results.

The influence of an electric current on plasticity has been investigated in former Soviet Union in the years 1960-1970 (Conrad et al. 1990), and by Sprecher et al (Sprecher et al. 1986). For example, Fig. 4 shows the effect of single high intensity $\left(\sim 10^{5}-10^{6} \mathrm{~A} / \mathrm{cm}^{2}\right)$ current pulses of short duration $(\sim 100 \mu \mathrm{s})$, on the strain rate of pure metals. It was verified that the current pulses did not increase the temperature by Joule effect by more than $\sim 0.5^{\circ} \mathrm{C}$. It can be seen that these high intensity current pulses can increase the deformation rate by orders of magnitude. Fig. 5 shows an interesting result of dislocation velocity $(v)$ measurements by the etch-pits technique in $\mathrm{Zn}$ at $78 \mathrm{~K}$ under the influence of short current pulses $\left(J=7.3 \times 10^{3} \mathrm{~A} / \mathrm{cm}^{2}\right.$, pulse duration: $200 \mu \mathrm{s})$, in function of an applied stress $(\tau)$. The current produced an increase in dislocation velocity for both the parallel and antiparallel directions (scalar effect), but larger for the first case, suggesting a vectorial contribution (electron wind effect). Again, the Joule heating generated by the current pulses was negligible $\left(\Delta \mathrm{T}<0.5^{\circ} \mathrm{C}\right)$. A more recent study showed that the elongation of a $\mathrm{Zn}-\mathrm{Al}$ alloy increased by a factor of $\sim 4$ under current pulses, this being in relation with TEM observations of acceleration of dislocation motion (Zhu et al. 2009).

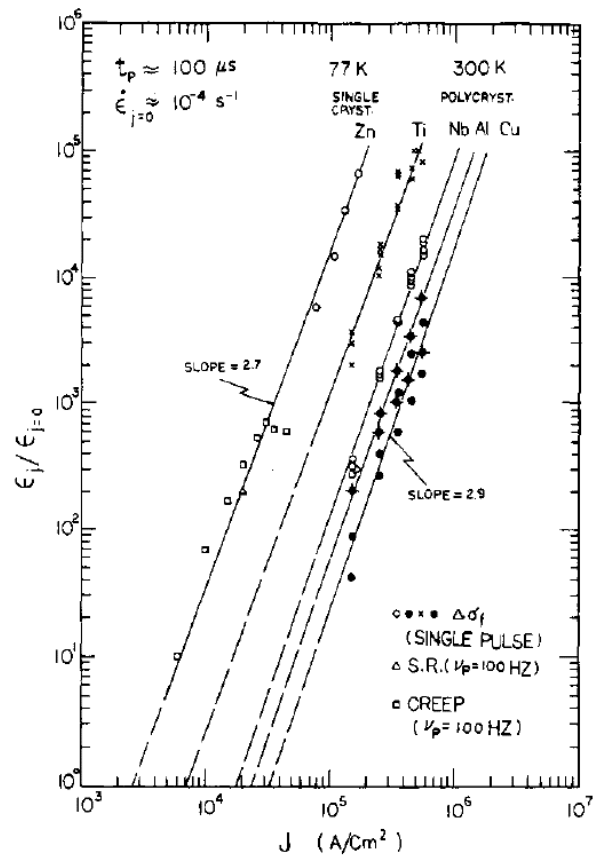

Fig. 4 Ratio of deformation rate with single current pulses $\left(\dot{\epsilon}_{\mathfrak{j}}\right)$ and without current pulses $\left(\dot{\epsilon}_{j=0}\right)$ of single and polycrystals of various pure metals, in function of the intensity of the current pulses (Conrad et al. 1990). 
Because of these effects, processing of metals by electroplastic manufacturing has been developed, as reviewed by by Guan et al. (Guan et al. 2010). This paper reports on many studies showing that under high intensity electric current pulses $\left(10^{3}-10^{5} \mathrm{~A} / \mathrm{cm}^{2}, 100 \mu \mathrm{s}\right)$, deformation resistance reduces markedly and, at the same time, plasticity increases significantly. For example, the elongation at room temperature of a $\mathrm{Zn}-\mathrm{Al}$ alloy is reported to increase by a factor of more than 4 under electropulsing $\left(1.6 \times 10^{3} \mathrm{~A} / \mathrm{cm}^{2}, 2300 \mu \mathrm{s}, 100 \mathrm{~Hz}\right)$.

However, the increase in dislocation velocity by electroplastic effect seems to be rather moderate (factor of 2 or so, Fig. 5), and this hardly account for the strong increase in deformation rates (Fig. 4). Thus, it appears that these electroplastic effects are still far from being well understood.

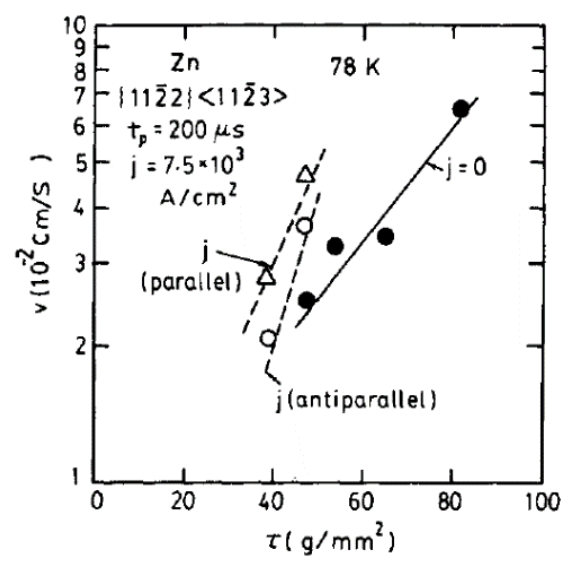

Fig. 5 Dislocation velocity in $\mathrm{Zn}$ at $78 \mathrm{~K}$ measured by etch-pits, under the influence of short current pulses $(J=7.3 \times 10-3 \mathrm{~A} / \mathrm{cm} 2$, pulse duration: $200 \mu \mathrm{s})$, in function of an applied stress ( $\tau)$ (Conrad et al. 1990).

An influence of electric currents on other metallurgical mechanisms (precipitation, recrystallization...) has also been reported (Conrad 2000). For example, current pulses $\left(8 \times 10^{4} \mathrm{~A} / \mathrm{cm}^{2}, 90 \mu \mathrm{s}, 2 \mathrm{~Hz}\right)$ decreased the time to reach $50 \%$ of recrystallization by a factor of $\sim 2$. This was interpreted by the fact that current pulses of the order of $10^{5} \mathrm{~A} / \mathrm{cm}^{2}$ ) cause about an order of magnitude increase in plastic strain rate, and presumably in dislocation velocity (Conrad et al. 1988).

\subsection{Conclusions}

In summary, strong currents are reported to exhibit significant effects on diffusion and plasticity kinetics, leading to higher deformability of metals. Therefore, the current pulses of the SPS technique can potentially increase the kinetics of sintering, through their impact on the elementary diffusion and plasticity mechanisms 
involved in densification. However, to observe significant current effects on diffusion and on plasticity, currents of at least $10^{2}-10^{3} \mathrm{~A} / \mathrm{cm}^{2}$ in the first case, and of $10^{3}-10^{6} \mathrm{~A} / \mathrm{cm}^{2}$ in the second, seem necessary. These values are at the upper limit or well above the average current passing through powders in typical SPS experiment $\left(\sim 10^{2} \mathrm{~A} / \mathrm{cm}^{2}\right)$. Thus, in that case, the current effects in the SPS process would be very limited. However, the local current densities at the contact areas between powder particles could be much higher than this average value, due to narrowing of the conducting section close the inter-particle contacts (see § 5.2). Consequently, current effects on diffusion and plasticity can potentially occur at the first sintering stage, when the contact areas between the powder particles are very small. We will discuss these questions in the next sections.

\section{Micromechanical models of densification under pressure}

For powders under pressure, densification can occur either by mass transport from the volume to the surface of the powder particles, or by deformation of the particles. In the second case, the particles can be deformed by dislocation mechanisms (glide, climb, twinning), or by mass transport within the volume of polycrystalline particles by volume (Nabarro-Herring creep) or grain-boundary (Coble creep) diffusion. Roughly speaking, deformation is the dominant mechanism for "big" powder particles, that is, for particles larger than a few micrometers. For "small" particles of diameters below a few micrometers, the capillary forces become strong enough to exceed the mechanical pressure, and in that case, densification occurs by mass transport. Micro-mechanical models have been derived to theoretically calculate the densification rates resulting from these mechanisms, and several reviews give the relevant expressions, for example Refs. (Arzt et al. 1983, Helle et al. 1985, Bernache-Assollant 1993, Davies et al. 1997, Duszczyk et al. 1998, Atkinson and Davies 2000, Rahaman 2003). However, in most practical cases, metallic powders processed by SPS are of sizes larger than about $10 \mu \mathrm{m}$, and the densification mechanism is deformation of the particles by the mechanical pressure, the deformation occurring either by dislocation mechanisms or by Nabarro-Herring or Coble creep. Tables 1 and 2 give the theoretical expression for densification in the two classical sintering stages: discrete particles touching at necks (stage $1, D<0.9$ ), and closure of porosity (stage $2, D>0.9$ ), $D$ being the relative density (density ratio of porous and fully dense states). 
Table 1. Theoretical expressions for densification in stage $1(D<0.9)$ (Davies et al. 1997).

\begin{tabular}{ll}
\hline Mechanism & Equation \\
\hline Plastic yield & $D=\left(\frac{\left(1-D_{0}\right) P}{1.3 \sigma_{y}}\right)^{1 / 3}$ \\
& $\dot{D}=5.3\left(D^{2} D_{0}\right)^{1 / 3} \frac{1}{\sqrt{3}}\left(\frac{D-D_{0}}{1-D_{0}}\right)^{1 / 2} A\left(\frac{P_{1 \mathrm{eff}}}{3}\right)^{n}$ \\
Power law creep & $\dot{D}=\frac{14.3}{D}\left(\frac{1-D_{0}}{D-D_{0}}\right)^{1 / 2}\left(\frac{D_{v}}{G^{2}}+\frac{\pi \delta D_{b}}{G^{3}}\right) \frac{\Omega}{k T} P_{1 \mathrm{eff}}$ \\
Nabarro-Herring and Coble creep & $\dot{D}=43\left(\frac{1-D_{0}}{D-D_{0}}\right)^{\frac{\delta}{R_{b}}} \frac{\Omega}{k T} P_{1 \mathrm{eff}}$ \\
Diffusion at the interparticle boundaries & $\dot{D}=32\left(1-D_{0}\right) \frac{D_{v}}{R^{2}} \frac{\Omega}{k T} P_{1 \mathrm{eff}}$ \\
Diffusion in the volume of the particles & $\dot{D}^{2}=3\left(1-D_{0}\right)$ \\
Effective pressure & $P_{1 \mathrm{eff}}=\frac{3 \gamma_{\mathrm{sv}}}{D^{2}\left(D-D_{0}\right)}+\frac{2 D-D_{0}}{R} D^{2}\left(\frac{D_{0}}{1-D_{0}}\right)$ \\
\hline
\end{tabular}

Table 2. Theoretical expressions for densification in stage $2(D>0.9)$ (Davies et al. 1997).

\begin{tabular}{ll}
\hline Mechanism & Equation \\
\hline Plastic yield & $D=1-\exp \left[\frac{-3\left(P-P_{0} \frac{\left(1-D_{c}\right) D}{(1-D) D_{c}}\right)}{2 \sigma_{y}}\right]$ \\
& $\dot{D}=\frac{3}{2} \cdot \frac{D(1-D)}{\left(1-(1-D)^{1 / n}\right)^{n}} A\left(\frac{3 P_{2 \text { eff }}}{2 n}\right)^{n}$ \\
Power law creep & $\dot{D}=32(1-D)\left(\frac{D_{v}}{G^{2}}+\frac{\pi \delta D_{b}}{G^{3}}\right) \frac{\Omega}{k T} P_{\text {2eff }}$ \\
Nabarro-Herring and Coble creep & $\dot{D}=4 \frac{\delta D_{b}}{R^{3}} \frac{\Omega}{k T} P_{2 \text { eff }}$ \\
Diffusion at the interparticle boundaries & $\dot{D}=3\left(\frac{1-D}{6 D}\right)^{1 / 2} \frac{D_{v}}{R^{2}} \frac{\Omega}{k T} P_{2 \mathrm{eff}}$ \\
Diffusion in the volume of the particles & $P_{2 \mathrm{eff}}=P+\frac{2 \gamma_{s v}}{R}\left(\frac{6 D}{1-D}\right)^{1 / 3}-P_{0} \frac{\left(1-D_{c}\right) D}{(1-D) D_{c}}$ \\
\hline
\end{tabular}


Table 3. Symbols used in Tables 1 and 2.

\begin{tabular}{ll}
\hline Symbol & Description \\
\hline$A$ & Creep constant in Norton law: $\dot{\varepsilon}=A \sigma^{n}, A=A_{0} \exp \left(-\frac{Q}{R T}\right)$ \\
$A_{0}$ & Constant \\
$D$ & Relative density \\
$\dot{D}$ & Densification rate $(=\mathrm{d} D / \mathrm{d} t)$ \\
$D_{0}$ & Initial relative density \\
$D_{\mathrm{c}}$ & Relative density at which pores close \\
$D_{v}$ & Volume diffusion coefficient \\
$\delta D_{v}$ & Grain boundary thickness $\times$ grain boundary diffusion coefficient \\
$\dot{\varepsilon}$ & Deformation rate \\
$G$ & Grain size \\
$k$ & Boltzmann's constant \\
$n$ & Stress exponent \\
$P$ & External pressure \\
$P_{0}$ & Outgassing pressure \\
$P_{\text {leff }}, P_{2 \text { eff }}$ & Effective pressure on necks during stage 1 or 2 \\
$Q$ & Activation energy \\
$R$ & Powder particle radius \\
$T$ & Temperature \\
$\Omega$ & Molecular volume \\
$\gamma_{\text {sv }}$ & Specific surface energy \\
$\sigma$ & Stress \\
$\sigma_{y}$ & Yield stress \\
\hline & \\
\hline
\end{tabular}

To conveniently analyze the densification curves, a rearrangement of Eqs. (2-7) for stage 1 has been proposed (Bernard-Granger and Guizard 2007):

$\frac{\dot{D}}{D}=\mu_{\mathrm{eff}} \cdot K \frac{\exp \left(\frac{-Q}{R T}\right)}{T}\left(\frac{b}{G}\right)^{p}\left(\frac{P_{1 \mathrm{eff}}}{\mu_{\mathrm{eff}}}\right)^{n}$

with:

$\mu_{\mathrm{eff}}=\frac{E}{2(1+v)} \cdot \frac{D-D_{0}}{1-D_{0}}$

$Q$ being the apparent activation energy of the mechanism controlling densification, $p$ the grain size exponent, $b$ the Burgers' vector, $v$ the Poisson's coefficient, $E$ the elastic modulus and $R$ the gas constant. Determination of stress exponent $n$ and of activation energy $Q$ is then possible by transformation of Equ. (14) as follows:

$\ln \left[\frac{1}{\mu_{\text {eff }}} \frac{\dot{D}}{D}\right]=n \ln \left[\frac{P_{1 \text { eff }}}{\mu_{\text {eff }}}\right]+K_{1}$

$\ln \left[\frac{T}{\mu_{\text {eff }}}\left(\frac{\mu_{\text {eff }}}{P_{1 \text { eff }}}\right)^{n} \frac{\dot{D}}{D}\right]=-\frac{Q}{R T}+K_{2}$

The slope of the curves in suitable coordinates gives thus $n$ and $Q$. 
However, for implementing the densification behavior of powders for elaborating complex shapes by SPS, the trend seems now to use theories based on continuum mechanics of compressible bodies, as reviewed by Olevsky (Olevsky 1998). As this subject is beyond the scope of the present review, the readers are invited to refer to the above paper.

\section{Densification by SPS: cycles and kinetics}

We indicate in this section typical SPS conditions employed for metallic systems, and the resulting densification cycles. Then, we report on studies analyzing the densification kinetics by the mechanical behavior of the powder at high temperature.

\subsection{Typical SPS conditions}

Typical SPS densification cycles of metals are as follows. The powder are enclosed into molds constituted of an electrically conducting material, in general graphite. The diameter of the molds are generally of a few centimeters in diameter, but dedicated SPS machines allow densifying samples of diameter up to $50 \mathrm{~cm}$. A graphite foil is introduced between the powder and the mold walls to insure lubrication and sealing. At the beginning of the SPS cycle, the chamber is evacuated to vacuum of $\approx 10 \mathrm{~Pa}$. The densification cycle begins $(\mathrm{t}=0)$ when the evacuation procedure is completed. A uniaxial pressure of $10 \mathrm{MPa}$ to $100 \mathrm{MPa}$ is applied rapidly (1 min), unless outgassing procedure under low applied loads are necessary. Simultaneously, the samples are heated up by increasing the intensity of the pulsed current applied to the graphite molds. If a pyrometer is employed for measuring the temperature, a special procedure is used for heating the samples below the minimum temperature that the pyrometer is able to detect. Then, temperature is increased at a rate of typically $100^{\circ} \mathrm{C} / \mathrm{min}$, sometimes more slowly for large specimen, rarely more rapidly. When temperature approaches the desired final value, the heating rate is frequently reduced, to avoid overtaking of this value (overshoot). Finally, the temperature is kept constant for a few minutes, sometimes for longer durations (up to 1 hour) if metallurgical transformations are necessary. At the end of the cycle, the heating current and the uniaxial pressure are released, and the samples cool down in the vacuum of the SPS chamber, at $100-500^{\circ} \mathrm{C} / \mathrm{min}$ depending on temperature and on mold size. Most of the time, the total duration of the SPS cycle is $\sim 30 \mathrm{~min}$. Fig. 6 shows an example of SPS cycle for TiAl powder (Trzaska et al. 2016). 


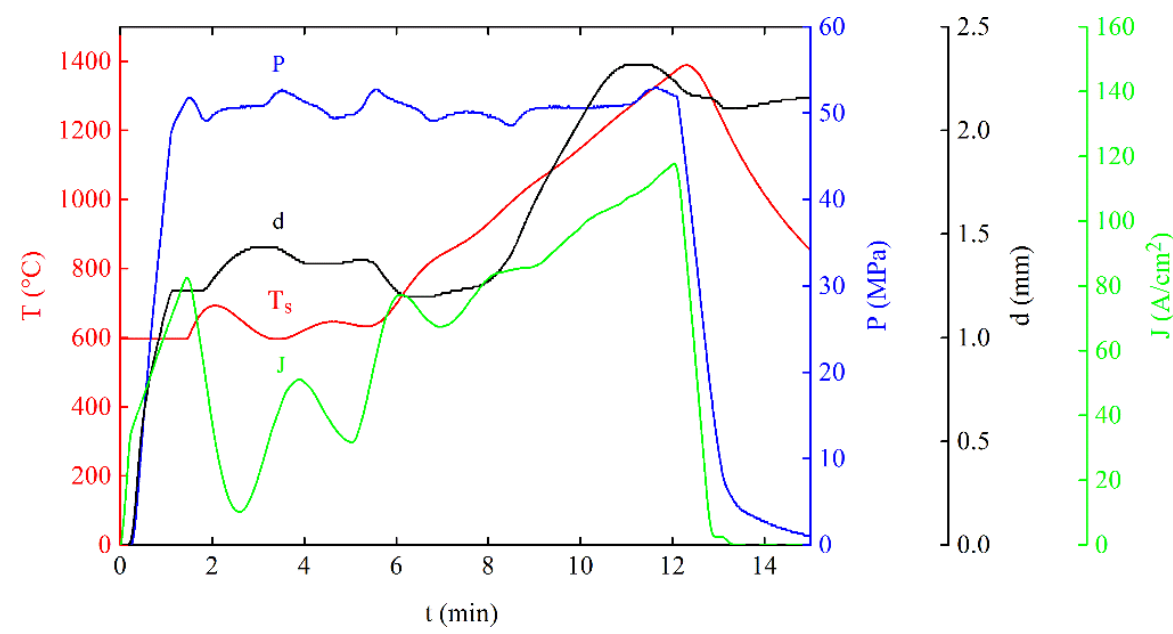

Fig. 6 Evolution of pressure $(P)$, sample temperature $\left(T_{\mathrm{s}}\right)$, current density $(J$, supposing that $30 \%$ of the current of the SPS go through the sample (Misawa et al. 2009)) and displacement of the lower punch ( $d$, positive when the punch goes up), during densification of a TiAl powder in a $20 \mathrm{~mm}$ graphite matrix (Trzaska et al. 2016).

The heating current is measured by a sensor which gives the total intensity (in Amperes). Because metallic powders exhibit most of the time a very high electric conductivity, a fraction of this current goes through the sample, the other fraction passing through the surrounding graphite mold. Experimental measurements of these fractions have been performed by Misawa et al. (Misawa et al. 2009). They show that, with $\mathrm{Cu}$ powder, about $30 \%$ of the total current goes through the samples, and then $70 \%$ through the molds (with $20 \mathrm{~mm}$ molds). Using this estimate, Fig. 6 shows that typical order of magnitude of currents passing through samples for electrically conducting metallic powders (here, TiAl) is $\sim 100 \mathrm{~A} / \mathrm{cm}^{2}$. Concerning the electric tension, its value is low, $\sim 2-5 \mathrm{~V}$.

Accurate determination of sample temperature is an important issue in the SPS experiments, because of the inhomogeneity of the current density in the samples and in the molds, which gives rise to strong temperature gradients (Munir et al. 2006). Temperature is measured by optical pyrometers, or by thermocouple. The inconvenient of pyrometers is that they work only from a minimum temperature, which can be elevated (e.g. $\sim 600^{\circ} \mathrm{C}$ ). This can be not suitable for some metals, and in that case, thermocouple are employed. However, the latter have the drawback to be very sensitive to thermal contact resistances, which can lead to underestimation of temperature and scattering of the measurements of $\sim 50^{\circ} \mathrm{C}$. Moreover, due to the temperature gradients in the molds and in the samples, and because the temperature is measured at the surface of the graphite molds, or inside them, there is a difference between the measured value and the sample temperature. There can also be significant temperature gradients within the samples (Voisin et al. 2013). To minimize these effects, modern SPS systems allow temperature to be measured very close to 
the sample by axial pyrometers. Nevertheless, temperature differences still remain, and calibration procedure based on melting of metals (e.g. Al, $\mathrm{Cu}$ (Trzaska et al. 2017)) or on solid-state phase transitions (e.g. TiAl a transition (Voisin et al. 2013)) can be necessary.

\subsection{Densification curves of ductile and brittle metallic systems}

Fig. 7 gives the evolution of the relative density of powders of metallic systems exhibiting emblematic mechanical behavior: brittle (TiAl) and ductile (Ni) (Trzaska et al. 2018). The striking feature is that in the two cases, densification occurs within minutes, that is, quite rapidly. In comparison, typical hot isostatic pressing (HIP) cycles for TiAl last several hours (Choi et al. 1990). However, the curves are also quite different. For TiAl, densification begins at $\sim 900^{\circ} \mathrm{C}$ and finishes at $\sim 1250^{\circ} \mathrm{C}$; the entire process thus takes place in a temperature range of $\sim 350^{\circ} \mathrm{C}$. Conversely, the densification of $\mathrm{Ni}$ extends over a much wider temperature range, beginning near room temperature, and ending above $1300^{\circ} \mathrm{C}$ (full density could not be reached before melting of the sample). This difference results mainly on the temperature dependence of the deformation rate of the powder particles, that is, on the activation energy. Thus, the lower activation energy of Ni powder compared to TiAl (164 \pm $30 \mathrm{~kJ} / \mathrm{mol}$ (Trzaska et al. 2018) and $308 \pm 20 \mathrm{~kJ} / \mathrm{mol}$ (Trzaska et al. 2017), respectively) accounts for the wider temperature range over which densification of $\mathrm{Ni}$ occurs as compared to TiAl.

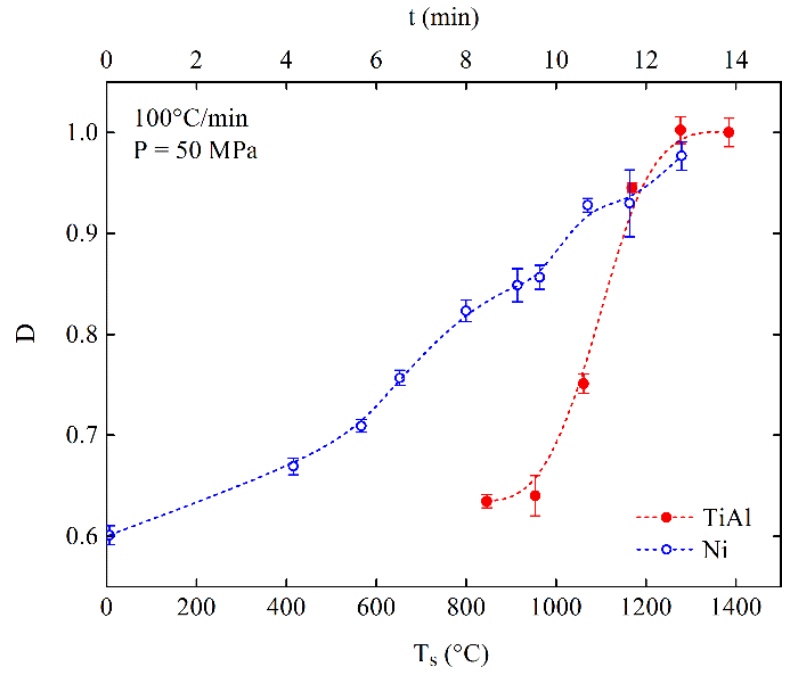

Fig. 7 Relative density as a function of time $(t)$ and of sample temperature $\left(T_{\mathrm{s}}\right)$ of TiAl and Ni processed by SPS using the conditions shown in Fig. 6 (Trzaska et al. 2018). 


\subsection{Determination of densification curve from bulk constitutive relations}

The SPS densification curves have been theoretically determined using the constitutive relation of the bulk material:

$\dot{\varepsilon}=A \sigma^{n}$

with:

$A=A_{0} \exp \left(-\frac{Q}{R T}\right)$

These relations have been used in micro-mechanical models (Equ. (3) and (9)) to calculate the densification curve of TiAl (Trzaska et al. 2017), or in continuum mechanics models to calculate the densification curves of $\mathrm{ZrC}$ (Wei et al. 2015) and of TiAl (Martins et al 2017). Fig. 8. Shows that the densification curve of TiAl powder, for example, can be quite accurately reproduced using the bulk parameters. The difficulty is to select the suitable $A_{0}, n$ and $Q$ values, which can vary a lot for a given material, even if the microstructures are similar. For near $\gamma \mathrm{TiAl}$ alloy of similar microstructures (grain size, fraction of residual $\alpha_{2}$ phase, etc.), the deformation rate $\dot{\varepsilon}$ can vary over one order of magnitude at least for given conditions (temperature, applied stress) depending on the authors (Trzaska et al. 2017). This impacts severely the calculated densification curves. Finally, order of magnitude of typical deformation rate $(\dot{\varepsilon})$ of the powder particles in SPS experiments is $10^{-3} \mathrm{~s}^{-1}$ (Trzaska et al. 2016), which gives bulk deformation $(\varepsilon)$ of the order of $30 \%$ at full densification.

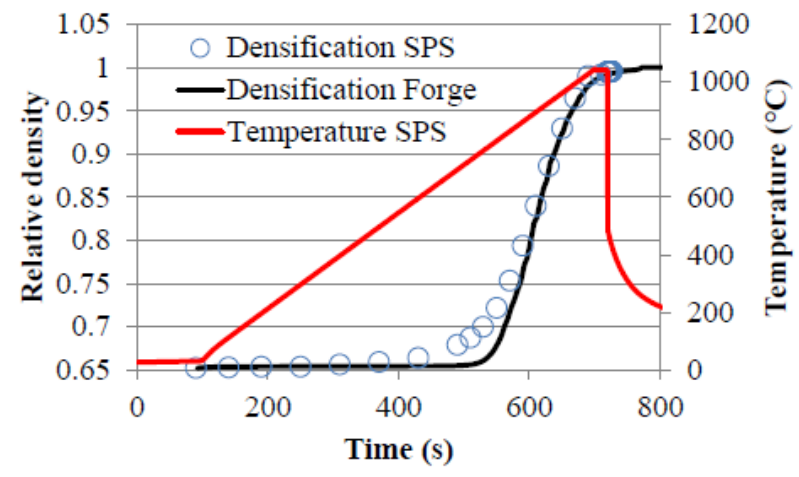

Fig. 8 Experimental SPS densification curve of a TiAl alloy, compared with calculated densification kinetics (using Forge software) using constitutive relation of bulk TiAl (parameters: $Q=414 \mathrm{~kJ} / \mathrm{mol}, n=2.81, A_{0}=3.14 \times 10^{-8} \mathrm{~Pa}^{-n} \mathrm{~s}^{-1}$ ) (Martins et al. 2017).

\subsection{Effect of current on densification rate}

Using dedicated sinter-forging devices, allowing densification in absence or in presence of SPS current ( 0 or $\sim 1000 \mathrm{~A} / \mathrm{cm}^{2}$ ) passing directly through highly conducting $(\mathrm{Cu})$ powders, it was reported that the final density was significantly higher with current (Fig. 9). This was attributed to electroplasticiy effects (Aleksandrova 
et al. 2015). On the contrary, with Cu powder processed by SPS ( $\sim 200 \mathrm{~A} / \mathrm{cm}^{2}$ passing through the powder by use of alumina dies) and by HP $\left(0 \mathrm{~A} / \mathrm{cm}^{2}\right)$, it was found that the densification cycle was essentially unaffected by the current (Collet et al. 2017). The same observation was made in SPS $\left(\sim 100 \mathrm{~A} / \mathrm{cm}^{2}\right)$ and HP $\left(0 \mathrm{~A} / \mathrm{cm}^{2}\right)$ experiments with a TiAl powder (Trzaska et al. 2017). The effect of the current on densification kinetics remains then controversial. However, it seems that increase in densification kinetics are observed only for high current densities $\left(\sim 1000 \mathrm{~A} / \mathrm{cm}^{2}\right.$ or so), that is, close to those for which electroplastic effects are observed (see $\S 2.2$ ).
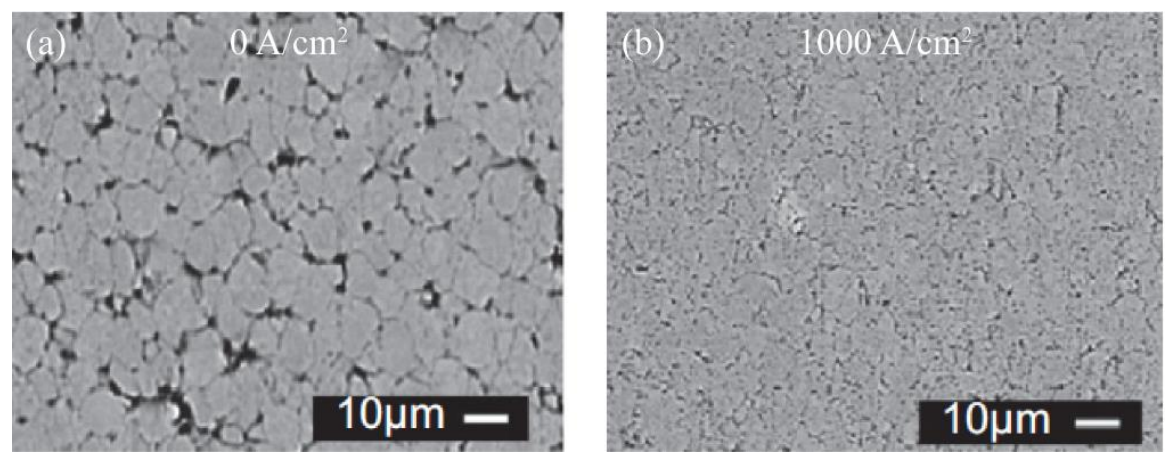

Fig. 9 Cross-sectional microstructure of $\mathrm{Cu}$ powder of $10 \mu \mathrm{m}$ in size densified without current (a), and with a current of $\sim 1000 \mathrm{~A} / \mathrm{cm}^{2}$ (b). Conditions: max. temperature: $575^{\circ} \mathrm{C}$, heating rate: $50^{\circ} \mathrm{C} / \mathrm{min}$, pressure: $10 \mathrm{MPa}$.

\subsection{Conclusions}

These results show that, under high currents $\left(\sim 1000 \mathrm{~A} / \mathrm{cm}^{2}\right)$, current-induced acceleration of densification is observed. With typical SPS currents $\left(\sim 100 \mathrm{~A} / \mathrm{cm}^{2}\right)$, the densification rate is identical than without current, and can be deduced from the high temperature mechanical behavior of the bulk material, meaning that densification is unaffected by the current.

\section{SPS microscopic mechanisms}

Because metallic powder particles are crossed by electric currents during densification by SPS, many modelling and experimental works have been carried out to investigate possible original electric phenomena, which can be classified as follows. (i) Dielectric breakdown of the thin oxide layer at the surface of the powder particles due to electric fields exceeding the dielectric strength of the oxide. (ii) Arcs and plasma due to ionization of the residual gas in the gaps between the powder particles. (iii) Increase in current density due to striction of the current lines at the small 
contact areas between the powder particles. Hypotheses (i) to (iii) were believed to generate local overheating in the vicinity of the necks between the powder particles, leading to local softening of the material, to easier welding and to faster densification. Finally, a last class of phenomena was (iv) activation of electromigration and/or electroplastic effects due to the strong current densities at the contact areas between the powder particles. These effects were supposed to modify the elementary plasticity and diffusion phenomena or their kinetics, and consequently to a modification of the densification rate. Simulation works mainly focused on point (iii), whereas most of the other phenomena have been investigated experimentally.

\subsection{Local overheating generated by arcs, plasma and dielectric breakdown}

Concerning the local generation of heat by arcs, plasma and dielectric breakdown, a complex scenario involving these phenomena was first proposed in Ref. (Tokita 1999). Then, experimental works on electric breakdown of oxide layers at the surface of the powder particles were reported by several authors (Omori 2000, Okazaki 2000, Groza and Zavaliangos 2000). These phenomena were believed to induce fast grain growth (Ye et al. 2006). Yanagisawa et al. (Yanagisawa et al. 2003) experimentally observed electric arcs between $\mathrm{Cu}$ powder particles $550 \mu \mathrm{m}$ in diameter subjected to macroscopic high intensity current pulses (1700$\left.17000 \mathrm{~A} / \mathrm{cm}^{2}\right)$ of $500 \mathrm{~ms}$ duration, in low-load (10 MPa) dedicated experiments (Fig. 10). These arcs provoked local melting at the necks between the powder particles. Saunders et al. (Saunders et al. 2015) have shown plasma formation in W particles $0.5 \mu \mathrm{m}$ in size for low applied tension $(<50 \mathrm{~V})$ and low applied pressure in emission spectroscopy (AES) experiments. However, an opposite conclusion has been obtained by Hulbert et al. (Hulbert et al. 2009), using also AES for investigating plasma formation with metallic and ceramic powders. Other studies on SEM observations of neck regions between $\mathrm{Cu}$ powder particles showed fine grains in these regions, which was interpreted as local melting followed by rapid solidification (Song et al. 2006). However, fine grains in the neck region can also result from recrystallization following intense plastic deformation by mutual indentation of the particles (Trzaska et al. 2016).
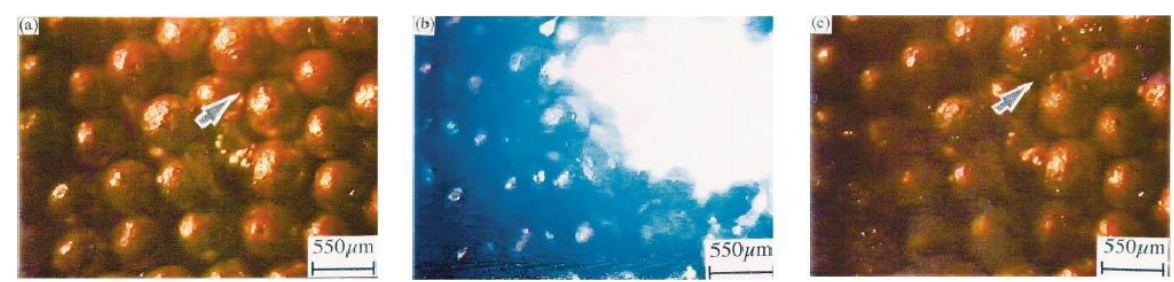

Fig. 10 Image sequence (time interval between each image: $0.02 \mathrm{~s}$ ) of an electric arc between $\mathrm{Cu}$ particles $550 \mu \mathrm{m}$ in diameter submitted to a single current pulse of $6700 \mathrm{~A} / \mathrm{cm}^{2}$ and of $100 \mathrm{~ms}$. Note the welding of the particles (image (c), arrow) resulting from local melting (Yanagisawa et al. 2003). 


\subsection{Local overheating generated by strong current densities at the necks}

This point is treated independently of the preceding, because many modelling studies have been performed around these ideas, which were first proposed in 1944 by Cramer (Orru et al. 2009). Due to the striction of the current lines at the small contact areas between the powder particles, very elevated heat generation by Joule effect (reaching $10000^{\circ} \mathrm{C}$ ) has been analytically calculated by several authors (Yanagisawa et al. 2003, Song et al. 2006, Diouf et al. 2013, Xiong et al. 2012) However, early works (Yanagisawa et al. 2003, Song et al. 2006) did not take into account heat conduction within the particles. More recent works have been conducted taking into account heat conduction, for millimetric or centimetric particles, and also calculated elevated temperatures at the particle contacts (Diouf 2013 et al., Xiong 2012 et al.). Trapp and Kieback (Trapp and Kieback 2015) evaluated by experiments and by simulation a Joule overheating of $0.05^{\circ} \mathrm{C}$ to $5^{\circ} \mathrm{C}$ at the contacts between $\mathrm{Cu}$ and steel spheres of $1 \mathrm{~mm}$ in diameter in capacitor discharge experiments, and concluded that, in normal operating conditions, essentially no temperature difference between contact and center of the particles should occur during SPS experiments. As can be seen, these studies predict temperature elevations (large or small) at the necks, but they concern particle sizes of millimeters to centimeters, i.e. much larger than the typical particle sizes used in SPS experiments (around 10-100 $\mu \mathrm{m}$ ). However, a recent modelling study (Collard et al. 2017) showed that, despite the current density could be $\sim 100$ times higher than the average current in the neck regions, very low temperature elevations would occur $\left(<1{ }^{\circ} \mathrm{C}\right)$. This was explained by the very fast heat diffusion at the scale of metallic powder particles $100 \mu \mathrm{m}$ in size, which temperature homogenization by heat diffusion took only milliseconds (Fig. 11).

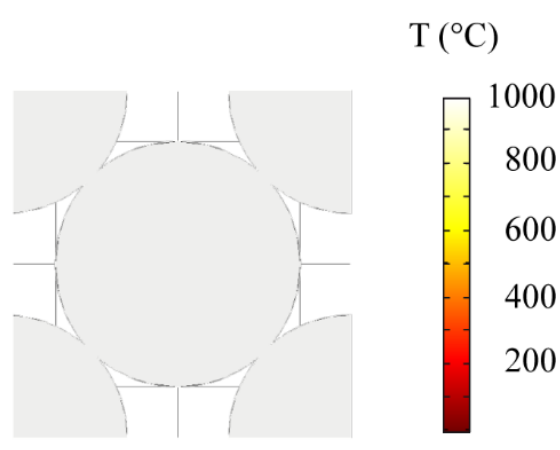

(a)

(b)

Fig. 11 FEM temperature maps in metallic powder particles $100 \mu \mathrm{m}$ in diameter heated by hot spots $\left(\mathrm{T} \approx 1000 \mathrm{C}^{\circ}\right)$ at their periphery, showing temperature homogenization in the particles within milliseconds. (a) Temperature map at $\mathrm{t}=0$. (b) Temperature map at $\mathrm{t}=4 \times$ $10^{-3} \mathrm{~s}$ (Collard et al. 2017). 
To experimentally investigate the hypothesis of local overheating, microstructure characterizations have been performed. For example, local melting in $\mathrm{FeAl}$ powder (Fig. 12) (Ji et al. 2007), or local devitrification in $\mathrm{Zr}_{57} \mathrm{Cu}_{20} \mathrm{Al}_{10} \mathrm{Ni}_{8} \mathrm{Ti}_{5}$ metallic glass powder (Nowak et al. 2011), have been reported.

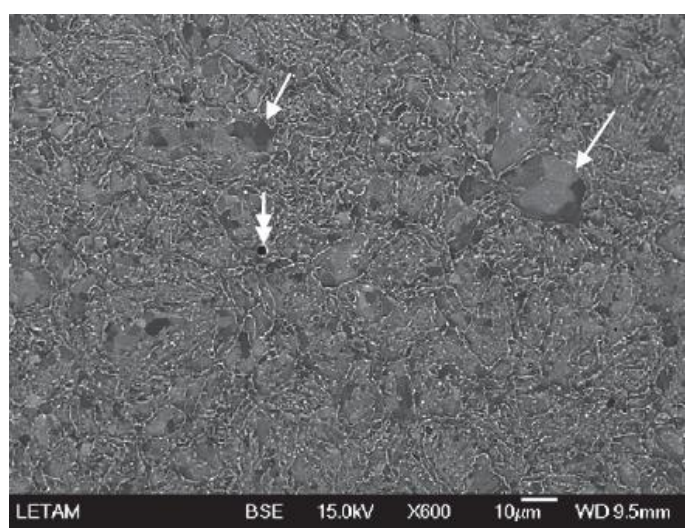

Fig. 12 SEM image of fairly large FeAl grains (single arrows) which formation is believed to result from melting due to local overheating (Ji 2007 et al.).

\subsection{Activation of electroplasticity and electromigration}

Another consequence of strong current densities at the necks between the powder particles is the potential activation of electroplastic and electromigration phenomena, which would accelerate densification. Values of $30-50 \times 10^{4} \mathrm{~A} / \mathrm{cm}^{2}$ can be reached at the necks between particles at early sintering stages according to modelling (Frei et al. 2007, Collard et al. 2017), an order of magnitude which is close to that necessary for electroplasticity $\left(10^{3}-10^{6} \mathrm{~A} / \mathrm{cm}^{2}\right)$, and even above that for which electromigration is reported $\left(10^{2}-10^{3} \mathrm{~A} / \mathrm{cm}^{2}\right)$, see $\S 2$. 

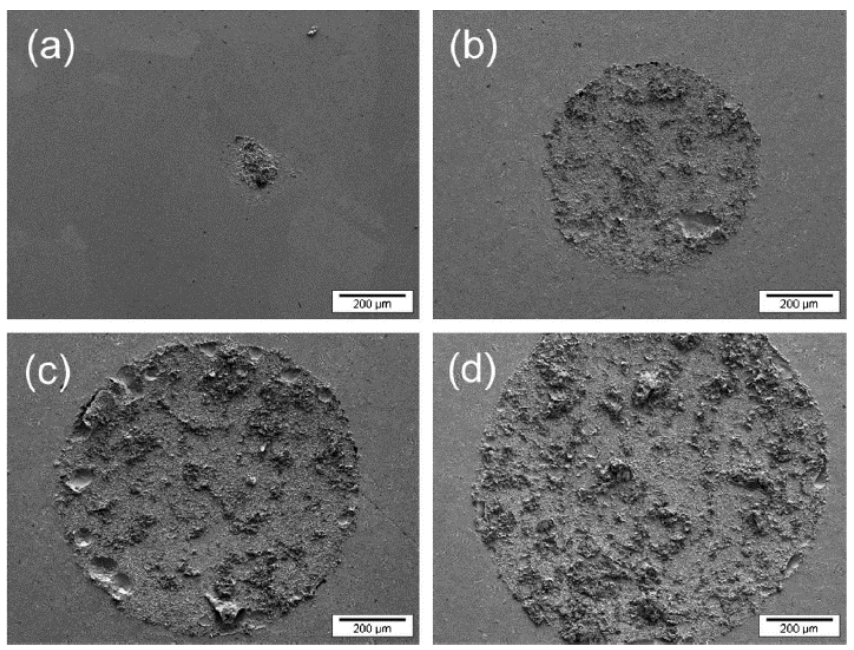

Fig. 13 Imprints of necks between $\mathrm{Cu}$ spheres and plates annealed $900{ }^{\circ} \mathrm{C}$ for $60 \mathrm{~min}$, with average current density of: (a) $0 \mathrm{~A} / \mathrm{cm}^{2}$, (b) $350 \mathrm{~A} / \mathrm{cm}^{2}$, (c) $420 \mathrm{~A} / \mathrm{cm}^{2}$, and (d) $520 \mathrm{~A} / \mathrm{cm}^{2}$.

Thus, Frei et al. (Frei et al. 2007) report model experiments by SPS of Cu spheres $3 \mathrm{~mm}$ in diameter in contact with $\mathrm{Cu}$ plates, to simulate the contacts between powder particles. Observation of enhanced neck growth was attributed to electromigration and evaporation-condensation phenomena activated by average currents of $350-520 \mathrm{~A} / \mathrm{cm}^{2}$ passing through the $\mathrm{Cu}$ spheres, but which could be much higher at the contact zones due to striction of the current lines (Fig. 13). Moreover, to investigate the mechanisms occurring under strong current densities at the necks of metallic particles, microstructure characterizations at fine scale (by EBSD and TEM) have been performed, involving notably careful procedure of TEM thin foil lift out at the necks by FIB (Fig. 14, Trzaska et al. 2016, Trzaska et al. 2018). Thus, in Ni, the neck regions exhibited intense plastic deformation by mutual indentation of the powder particles, leading to formation of cell boundaries (Fig. 14 a and c). Analysis of elementary microscopic mechanisms in TiAl showed screw dislocations, loops and probably helices, indicating glide and climb mechanisms (Fig. 14d). In both cases, the proposed elementary mechanisms controlling the dislocation processes were diffusion in volume for TiAl, and in dislocations for Ni. This plastic deformation was followed by recovery and recrystallization in TiAl. These mechanisms appeared classical, without any obvious modification induced by the strong current at the necks. 

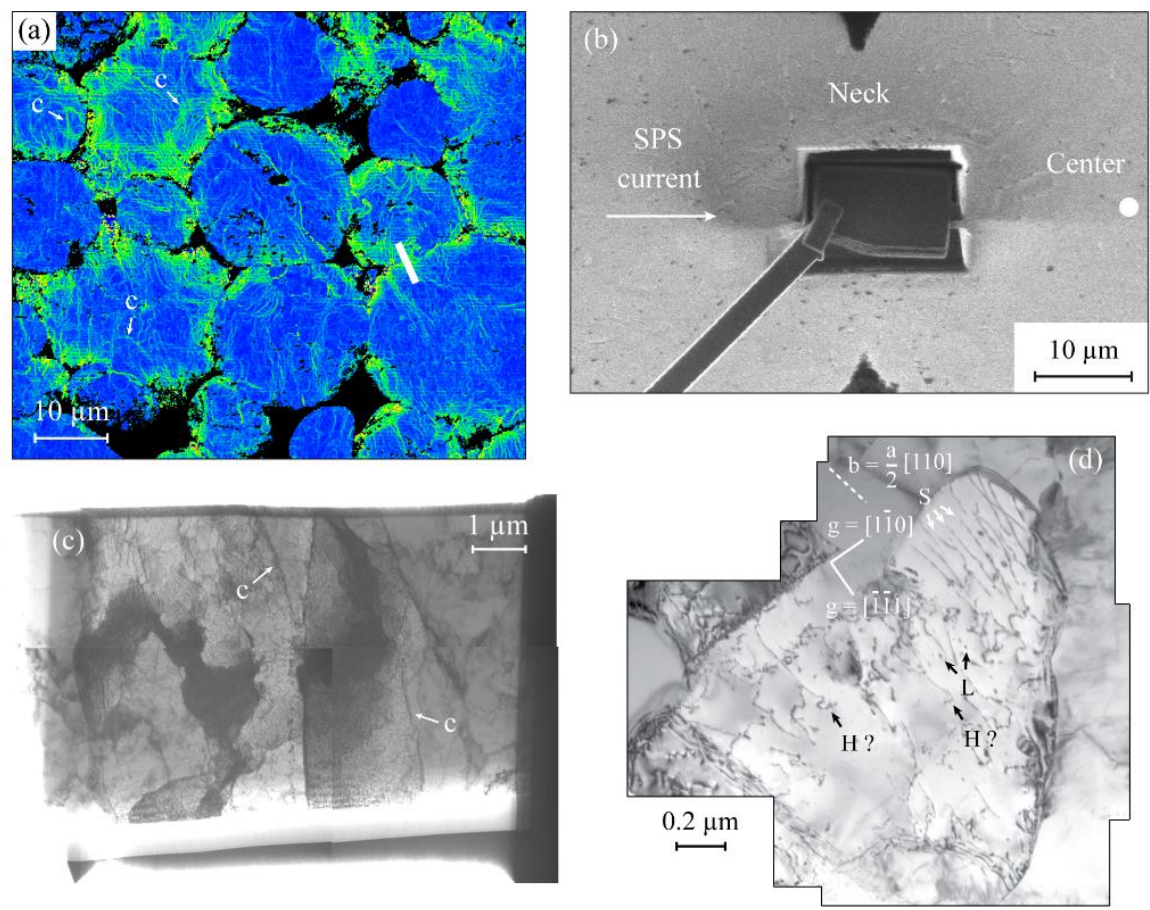

Fig. 14 (a) EBSD local misorientation map Ni powder during densification by SPS $\left(512^{\circ} \mathrm{C}\right.$, $D=0.7$ ). Typical location of FIB extraction is indicated by a white segment. Deformation cells are labelled as c. (b) Extraction of a TEM thin foil by FIB in a neck region. (c) TEM image of an entire FIB thin foil extracted at the junction between two Ni particles in a sample densified at $727^{\circ} \mathrm{C}(\mathrm{D} \approx 0.75)$. Dislocation walls are labelled as c. (c) TEM bright field image of a TiAl $\gamma$ grain in a neck region (densification interrupted at $1040^{\circ} \mathrm{C}, \mathrm{D}=0.7$ ). Screw dislocations, helices and loops are indicated by letters $\mathrm{S}, \mathrm{H}$ and $\mathrm{L}$, respectively (Trzaska et al. 2016, Trzaska et al. 2018).

\subsection{Conclusions}

In summary, the existence of significant heat generation by spark and plasma, as well as by striction of the current lines at the necks between powder particles, is still controversial. However, the recent theoretical works tend to demonstrate that overheating by striction of the current lines is probably low. Arcing phenomena by ionization of the residual gas between the powder particles, or by dielectric breakdown of the superficial oxide layers, seem to occur in particular conditions (low load $\sim 10 \mathrm{MPa}$, current pulses $\sim 10000 \mathrm{~A} / \mathrm{cm}^{2}$ ), not really representative of typical SPS conditions. However, increase in neck growth rate by electrically-enhanced mass transport was observed for lower average current densities $\left(350-520 \mathrm{~A} / \mathrm{cm}^{2}\right)$, close to typical currents of SPS experiments. At the microscopic scale, the elementary mechanisms which were observed in the neck regions were dislocation (glide, 
climb) and recovery-recrystallization mechanisms, that is, classical high temperature phenomena. Thus, the SPS currents seem not to activate new mechanism, but could modify their kinetics.

\section{Conclusions}

Many of the microscopic phenomena described in literature to account for the high SPS kinetics remain controversial, but some conclusions can be drawn. It seems then established that the densification rate of metallic powders can be deduced directly from the high temperature mechanical behavior (power-law creep) of the bulk material. The rapidity of the SPS process is then a consequence of the high deformation rate of the powder particles $\left(\dot{\varepsilon} \sim 10^{-3} \mathrm{~s}^{-1}\right)$. Concerning the role of the current, typical SPS average currents are $\sim 100 \mathrm{~A} / \mathrm{cm}^{2}$. At the early sintering stages, the contact areas between powder particles are very small. This could give rise to strong striction of the current lines, and local current densities could reach much higher values $\left(10^{4}-10^{5} \mathrm{~A} / \mathrm{cm}^{2}\right)$. Thus, activation of arcing, of electroplasticity or of electromigration phenomena (triggered by current densities of $\sim 10^{4} \mathrm{~A} / \mathrm{cm}^{2}$, of $10^{3}-10^{6} \mathrm{~A} / \mathrm{cm}^{2}$ and of $10^{2}-10^{3} \mathrm{~A} / \mathrm{cm}^{2}$, respectively), is in principle possible. But, because most of metallic systems exhibit significant plasticity at high temperature, the contact zones between particles are quickly deformed under the action of the applied pressure. This drastically reduces the phenomenon of striction of the current lines, and the local current density comes back close to the average value $\left(\sim 100 \mathrm{~A} / \mathrm{cm}^{2}\right)$. Thus, electric phenomena can potentially play a short transitory role in the very early stages of densification, but then most of the densification probably occurs without influence of the electric current, and involves classical microscopic mechanisms.

\section{Acknowledgements}

This work is partially supported by the MF2-ANR-2011-PBS09-020 project of the French "Agence Nationale de la Recherche." The authors also gratefully acknowledge the helpful comments and suggestions of the reviewers, which have improved the presentation. 


\section{References}

Adda Y, Philibert J (1966) La diffusion dans les solides. Institut national des sciences et techniques nucléaires, Saclay

Aleksandrova EV, Ilyina AM, Grigoryev EG, Olevsky EA (2015) J Am Ceram Soc 98:35093517

Arzt E, Ashby MF, Easterling KE (1983) Practical applications of hot-isostatic pressing diagrams: four case studies. Metallurgical Transactions A 14:211-221

Atkinson HV, Davies S (2000) Fundamental aspects of hot-isostatic pressing: an overview. Metallurgical and Materials Transactions A 31:2981-3000

Bernache-Assolant D (1993) Chimie-physique du frittage. Hermès, Paris

Bernard-Granger G, Guizard C (2007) Spark plasma sintering of a commercially available granulated ziconia powder: I. Sintering path and hypotheses about the mechanism(s) controlling densification. Acta Materialia 55:3493-3504

Bertolino N, Garay J, Anselmi-Tamburini U, Munir ZA (2001) Scripta Materialia 44:737742

Chen SW, Chen CM, Liu WC (1998) Journal of Electronic Materials 27:1193-1199

Chen CM, Chen SW (1999) Journal of Electronic Materials 28:902-906

Chen CM, Chen SW (2000) Journal of Electronic Materials 29:1222-1228

Choi BW, Deng YG, McCullough C, Paden B, Mehrabian R (1990) Densification of rapidly solidified titanium aluminied powders - I. Comparison of experiments to hiping models. Acta Metallurgica et Materialia 38:2225-2243

Collard C, Trzaska Z, Durand L, Chaix JM, Monchoux JP (2017) Theoretical and experimental investigations of local overheating at particle contacts in spark plasma sintering. Powder Technology 321:458-470

Collet R, Le Gallet S, Naimi F, Charlot F, Lay S, Bonnefont G, Fantozzi G, Chaix JM, Bernard F (2017) Current effect on the sintering by SPS of a pre-oxidized copper powder. Journal of Alloys and Compounds 692:478-484

Conrad H, Karam N, Mannan S, Sprecher AF (1988) Effect of electric current pulses on the recrystallization kinetics of copper. Scripta Metallurgica 22:235-238

Conrad H, Sprecher AF, Cao WD, Lu XP (1990) Electroplasticity - the effect of electricity on the mechanical properties of metals. JOM 42:28-33

H. Conrad (2000) Effects of electric current on solid state phase transformations in metals. Materials Science and Engineering A 287:227-237

Davies GC, Jones DRH (1997) Creep of metal-type organic compounds - IV. Application to hot isostatic pressing. Acta Materialia 45:775-789

Diouf JS, Fedrizzi A, Molinari A (2013) A fractographic and microstructural analysis of the neck regions of coarse copper particles consolidated by SPS. Powder Technol 221:220227

Duszczyk J, Zhuang LZ, Buekenhout L (1998) Densification of a rapidly solidified nickel aluminide powder - I. Application of hot-isostatic pressing diagrams. Journal of Materials Science 33:2735-2743

Frankovic R (1996) Electromigration drift and threshold in $\mathrm{Cu}$ thin-film interconnect. IEEE Transactions on Electron Devices 43:2233-2239

Frei JM, Anselmi-Tamburini U, Munir ZA (2007) Current effects on neck growth in the sintering of copper spheres to copper plates by the pulsed electric current method. Journal of Applied Physics 101:114914

Friedman JR, Garay JE, Anselmi-Tamburini U, Munir ZA (2004) Intermetallics 12:589-597

Garay JE, Anselmi-Tamburini U, Munir ZA (2003) Acta Materialia 51:4487-4495 
Groza JR, Zavaliangos A (2000) Sintering activation by external electrical field. Materials Science and Engineering A 287:171-177

Guan L, Tang G, Chu PK (2010) Recent advances and challenges in electroplastic manufacturing processing of metals. J. Mater. Res. 25:1215-1224

Helle AS, Easterling KE, Ashby MF (1985) Hot-isostatic pressing diagrams: new developments. Acta Metallurgica 33:2163-2174

Hulbert DM, Anders A, Andersson J, Lavernia EJ, Mukherjee AK (2009) A discussion on the absence of plasma in spark plasma sintering. Scripta Materialia 60:835-838

Ji G, Grosdidier T, Bozzolo N, Launois S (2007) The mechanisms of microstructure formation in a nanostructured oxide dispersion strengthened FeAl alloy obtained by spark plasma sintering. Intermetallics 15:108-118

Liu WC, Chen SW, Chen CM (1998) Journal of Electronic Materials 27:L5

Martins D, Grumbach F, Manière C, Sallot P, Mocellin K, Bellet M, Estournès C (2017) Insitu creep law determination for modeling spark plasma sintering of TiAl 48-2-2 powder. Intermetallics 86:147-155

Misawa T, Shikatani N, Kawakami Y, Enjoji T, Ohtsu Y, Fujita H (2009) Observation of internal pulsed current flow through the $\mathrm{ZnO}$ specimen in the spark plasma sintering method. Journal of Materials Science 44:1641-1651

Munir ZA, Anselmi-Tamburini U, Ohyanagi M (2006) The effect of electric field and pressure on the synthesis and consolidation of materials: a review of the spark plasma sintering method. Journal of Materials Science 41:763-777

Nowak S, Perrière L, Dembinski L, Tusseau-Nenez S, Champion Y (2011) Approach of the spark plasma sintering mechanism in $\mathrm{Zr} 57 \mathrm{Cu} 20 \mathrm{Al10Ni8Ti5}$ metallic glass. Journal of Alloys and Compounds 509:1011-1019

Okazaki K (2000) Materials Science and Engineering A 287:189-197

Olevsky EA (1998) Theory of sintering: from discrete to continuum. Materials Science and Engineering R 23:41-100

Omori M (2000) Sintering, consolidation, reaction and crystal growth by the spark plasma system (SPS) Materials Science and Engineering A 287:183-188

Orru R, Licheri R, Locci AM, Cincotti A, Cao G (2009) Consolidation/synthesis of materials by electric current activated/assisted sintering. Mater. Sci. Eng. R 63:127-287

Rahaman MN (2003) Ceramic processing and sintering. Taylor and Francis, Boca Raton

Saunders T, Grasso S, Reece MJ (2015) Plasma formation during electric discharge (50 V) through conductive powder compacts. Journal of the European Ceramic Society 35:871877

Shewmon P (1989) Diffusion in solids. The Minerals, Metals and Materials Society, Warrendale

Song X, Liu X, Zhang J (2006) Neck Formation and Self-Adjusting Mechanism of Neck Growth of Conducting Powders in Spark Plasma Sintering. J. Am. Ceram. Soc. 89:494500

Sprecher AF, Mannan SL, Conrad H. On the mechanisms for the electroplastic effect in metals (1986) Acta Metall. $34: 1145-1162$.

Tokita M (1999) Development of large-size ceramic/metal bulk FGM fabricated by spark plasma sintering. Materials Science Forum 308-311:83-88

Trapp J, Kieback B (2015) Temperature distribution in metallic powder particles during initial stage of field-activated sintering. J. Am. Ceram. Soc. 98:3547-3552

Trzaska Z, Monchoux JP (2015) Electromigration experiments by spark plasma sintering in the silver-zinc system. Journal of Alloys and Compounds 635:142-149

Trzaska Z, Couret A, Monchoux JP (2016) Spark plasma sintering mechanisms at the necks between TiAl powder particles. Acta Materialia 118:100-108 
Trzaska Z, Bonnefont G, Fantozzi G, Monchoux JP (2017) Comparison of densification kinetics of a TiAl powder by spark plasma sintering and hot pressing. Acta Materialia $135: 1-13$

Trzaska Z, Cours R, Monchoux JP (2018) Densification of Ni and TiAl by SPS: kinetics and microscopic mechanisms. Metallurgical and Materials Transactions A, doi:10.1007/s11661-018-4775-0, in press

Voisin T, Durand L, Karnatak N, Le Gallet S, Thomas M, Le Berre Y, Castagné JF, Couret A (2013) Temperature control during Spark Plasma Sintering and application to up-scaling and complex shaping. Journal of Materials Processing Technology 213:269-278

Wang CH, Kuo CY, Chen HH, Chen SW (2011) Intermetallics 19:75-80

Wei X, Back C, Izhvanov O, Khasanov OL, Haines CD, Olevsky EA (2015) Spark plasma sintering of commercial zirconium carbide powders: densification behavior and mechanical properties. Materials 8:6043-6061

Xiong Y, Liu D, Li Y, Zheng B, Haines C, Paras J, Martin D, Kapoor D, Lavernia EJ, Schoenung JM (2012) Spark plasma sintering of cryomilled nanocrystalline Al alloy - Part I: microstructure evolution. Metallurgical and Materials Transactions A 43:327-339

Yanagisawa O, Kuramoto H, Matsugi K, Komatsu M (2003) Observation of particle behavior in copper powder compact during pulsed electric discharge. Materials Science and Engineering A 350:184-189

Ye J, Ajdelsztajn L, Schoenung J (2006) Metall. Mater. Trans. A 37:2569-2579

Zhao J, Garay JE, Anselmi-Tamburini U, Munir ZA (2007) Journal of Applied Physics 102 (2007) 114902

Zhou Y, Wang Q, Sun DL, Han XL (2011) Journal of Alloys and Compounds 509:12011205

Zhu YH, To S, Lee WB, Liu XM, Jiang YB, Tang GY (2009) Effects of dynamic electropulsing on microstructure and elongation of a $\mathrm{Zn}-\mathrm{Al}$ alloy. Materials Science and Engineering A 501:125-132 